\title{
BMR
}

\section{Identification of Uvaria sp by barcoding coupled with high-resolution melting analysis (Bar-HRM)}

\author{
M. Osathanunkul', P. Madesis ${ }^{2}$, S. Ounjai', K. Pumiputavon ${ }^{1}$, R. Somboonchai ${ }^{3}$, \\ P. Lithanatudom ${ }^{1}$, T. Chaowasku' ${ }^{1}$, J. Wipasa ${ }^{4}$ and C. Suwannapoom ${ }^{5}$ \\ 1'Department of Biology, Faculty of Science, Chiang Mai University, \\ Chiang Mai, Thailand \\ ${ }^{2}$ Institute of Applied Biosciences, Centre for Research \& Technology Hellas, \\ Thessaloniki, Greece \\ ${ }^{3}$ Program of Geosocial Based Sustainable Development, \\ Faculty of Agricultural Production, Maejo University, Chiang Mai, Thailand \\ ${ }^{4}$ Research Institute for Health Sciences Chiang Mai University, \\ Chiang Mai, Thailand \\ ${ }^{5}$ School of Agriculture and Natural Resources, University of Phayao, \\ Phayao, Thailand \\ Corresponding author: M. Osathanunkul \\ E-mail: omaslin@gmail.com \\ Genet. Mol. Res. 15 (1): gmr.15017405 \\ Received August 10, 2015 \\ Accepted October 15, 2015 \\ Published January 13, 2016 \\ DOI http://dx.doi.org/10.4238/gmr.15017405
}

ABSTRACT. DNA barcoding, which was developed about a decade ago, relies on short, standardized regions of the genome to identify plant and animal species. This method can be used to not only identify known species but also to discover novel ones. Numerous sequences are stored in online databases worldwide. One of the ways to save cost and time (by omitting the sequencing step) in species identification is to use available barcode data to design optimized primers for further analysis, such as high-resolution melting analysis (HRM). This study aimed to determine the effectiveness of the hybrid method Bar-HRM (DNA barcoding combined with HRM) to identify species that share similar external morphological features, rather than conduct traditional taxonomic identification that 
require major parts (leaf, flower, fruit) of the specimens. The specimens used for testing were those, which could not be identified at the species level and could either be Uvaria longipes or Uvaria wrayias, indicated by morphological identification. Primer pairs derived from chloroplast regions (matK, psbA-trnH, rbcL, and trnL) were used in the Bar-HRM. The results obtained from psbA-trnH primers were good enough to help in identifying the specimen while the rest were not. Bar-HRM analysis was proven to be a fast and cost-effective method for plant species identification.

Key words: Barcoding; High-resolution melting; Species identification; Uvaria sp; Chloroplast genes

\section{INTRODUCTION}

Over the last decade, DNA barcoding has enabled researchers to change the process of species identification. DNA barcoding is based on sequence diversity within a short and standardized gene region for species discrimination. The method can not only identify known species but also discover novel ones (Hebert et al., 2003; Mitchell, 2008). DNA barcoding involves isolating DNA from the organism of interest, performing polymerase chain reaction (PCR) of a selected region, sequencing the PCR product, and identifying the organism by comparing the sequence to a database (Hajibabaei et al., 2006; Hebert et al., 2004, 2010; Van der Bank et al., 2012; Franzini et al., 2013).

The rich online database of sequences can be used for designing optimized primers for further investigation such as high-resolution melting (HRM) analysis, and can be highly effective in saving cost and time for species identification because the relatively expensive and time-consuming sequencing step could be skipped.

Annonaceae is the most species-rich family of Magnoliales, comprising about 2400 species belonging to 108 genera (Rainer and Chatrou, 2006). It has long been referred to as a complex phylogenetic and taxonomic group. The Annonaceae classifications were proposed based on different sources of data: morphological characters (Hutchinson, 1923; Fries, 1959) and phylogenetic analysis (Doyle and Le Thomas, 1994; Mols et al., 2004; Pirie et al., 2006; Couvreur et al., 2008; Chatrou et al., 2012) but the classification not yet stable as newly discovered diversity of the family is being reported. Morphological characters that have been used in the family classification were floral, fruit, and seed morphology. The most widely used factor for Annonaceae classification seems to be the one introduced by Fries (1959), primarily based on floral characters.

In this study, we focused on the genus Uvaria L., which is one of the largest paleotropical genera in the family Annonaceae (Keßler, 1993), with 210 species. Uvaria L. are mainly woody climbers and scandent shrubs, found in the wet tropical forests in Africa, Madagascar, continental

Asia, Malaysia, northern Australia, and Melanesia. The genus has its center of diversity in continental Southeast Asia and Malaysia (Meade, 2005).

Uvaria L. is characterized by a combination of morphological features, including stellate hairs (throughout the plant), generally valvate sepals, partially or fully imbricate petals, numerous stamens and carpels, inaperturate monad pollen, and generally many seeded apocarpous fruits (Meade, 2005; Zhou et al., 2009).

The major distinguishing feature of the two closely related Uvaria species - Uvaria 
longipes and Uvaria wrayi - is flower morphology, although other morphological features such as fruit shape, leaf, and pollen are also important for species delimitation in Uvaria. The Uvaria $\mathrm{sp}$ plant was collected but could not be identified at the species level due to the lack of flowers. The taxonomy is further confounded by the high morphological similarity between $U$. longipes and $U$. wrayi; considering the morphological features, the sample could be either $U$. longipes or $U$. wrayi. Consequently, it becomes necessary to search for an alternative method to augment traditional morphology-based taxonomy of these species.

DNA barcoding was developed about a decade ago, and it relies on short, standardized regions of the genome to identify plant and animal species (Hebert et al., 2003). DNA barcoding has been widely studied and it is a powerful method for identification of plant species (Kress and Erickson, 2007; Fazekas et al., 2008; CBOL Plant Working Group, 2009). However, DNA barcoding in plants has limitations, such as the inability to amplify marker regions due to degraded DNA in processed samples (Särkinen et al., 2012), limited binding site universality (Sass et al., 2007; Kool et al., 2012), low rates of discrimination capabilities with certain markers (Stoeckle et al., 2011; Kool et al., 2012), overlapping intraspecific and interspecific genetic variation in some groups of plants (Fazekas et al., 2009), and low applicability of chloroplast markers for identification of species of hybrid origin (Fazekas et al., 2009). Another drawback of DNA barcoding is its cost: it requires a molecular laboratory, specialized equipment, chemicals, disposables, and DNA sequencing facilities. In developing countries, in particular, the lack of access to DNA sequencing facilities greatly hinders the wider implementation of DNA barcoding. There is a strong need for developing and validating a method that is reliable, but quicker and more economical than DNA barcoding. In this study, we combined DNA barcoding with HRM analysis for plant species identification.

$\mathrm{HRM}$ is an emerging method for monitoring DNA dissociation ("melting") kinetics, and is a powerful technique for the detection of point mutations, indels, and methylated DNA (Reja et al., 2010). The denaturation thermodynamics of individual DNA double strands to single strands are based on the binding affinities of individual nucleotide pairs, and the melting pattern varies due to indels, mutations, and methylations. Fluorescent measurements are collected at standard temperature increments during HRM cycles, and then plotted as a "melting curve". The curve's shape and peak are characteristic for each sample, facilitating comparison and discrimination among samples. Using this method, even a single-base change between samples can be readily detected and identified (Ririe et al., 1997; Wittwer et al., 2003).

We propose that DNA barcoding in combination with HRM (in other words, Bar-HRM) may provide a novel, complementary tool to ease species identification in cases in which major distinguishing features of the plant cannot be found. In this study, we evaluated the efficacy of BarHRM analysis as a tool to augment morphological species discrimination of three Uvaria species. Specifically, we assessed the potential of four plastid markers to identify an unknown Uvaria plant sample, which could not be identified using morphological features alone.

\section{MATERIAL AND METHODS}

\section{DNA mining of barcode regions}

Sequences for selected plastid regions (matK, $p s b \mathrm{~A}-t r n \mathrm{H}, r b c \mathrm{~L}$, and $t r n \mathrm{~L}$ ) were retrieved from NCBI GenBank (National Center for Biotechnology Information, USA). Low-quality sequences and accessions without specified herbarium vouchers were discarded. Analyses of all downloaded 
sequences were performed using multiple-sequence alignments made using the SeqMan Pro software program (DNASTAR, Inc., Madison, WI, USA), ClustalX2 (Larkin et al., 2007), and MEGA5 (Tamura et al., 2011). Variable characters and GC (guanine-cytosine) content were recorded.

\section{Plant materials and DNA isolation}

Three Uvaria species were used as plant materials for the analysis. The species and their locations are listed in Table 1. Plant samples were ground with liquid nitrogen, and $100 \mathrm{mg}$ of the material was used for DNA extraction using a NucleoSpin Plant ${ }^{\circledR}$ II (Macherey-Nagel, Düren, Germany) kit following manufacturer instructions. The DNA was stored at $-20^{\circ} \mathrm{C}$ for further use.

\begin{tabular}{lclr}
\multicolumn{2}{l}{ Table 1. Species and location of plants included in this study. } \\
\hline Species & Abbreviation & Location & Coordinates \\
\hline Uvaria cf. longipes & L1 & Khao Hin Son Botanical Garden & $13.749527,101.505463$ \\
& L2 & Phanomsarakham, Chachoengsao & $13.790384,100.372378$ \\
Uvaria siamensis & $\mathrm{S}$ & Taweewattana, Bangkok & $18.802350,98.952653$ \\
Uvaria cf. wrayi & W1 & Dept. of Biology Cultivated Plantation & $13.749527,101.505463$ \\
& W2 & Kaculty of Science, Chiang Mai University & $13.749527,101.505463$ \\
& & Khao Hin Son Botanical Garden & \\
Uvaria sp & Khanomsarakham, Chachoengsao & $13.790384,100.372378$ \\
\hline
\end{tabular}

\section{HRM method}

DNA amplification using real-time PCR was performed using the Eco Real-Time PCR (RT-PCR) system (Illumina ${ }^{\circledR}$, San Diego, CA, USA) in order to establish characteristic melting temperatures $(\mathrm{Tm})$ to enable the distinction of the different medicinal plants. The reaction mixture (total volume $10 \mu \mathrm{L}$ ) for the RT-PCR and HRM analysis consisted of $5 \mu \mathrm{L} 2 \mathrm{X}$ THUNDERBIRD ${ }^{\circledR}$ SYBR $^{\circledR}$ qPCR Mix, $0.2 \mu \mathrm{M}$ forward primer, $0.2 \mu \mathrm{M}$ reverse primer, and $1 \mu \mathrm{L} 25 \mathrm{ng} / \mu \mathrm{L}$ DNA. The primer pairs used for each region are listed in Table 2. SYBR fluorescence dye was used to monitor the accumulation of the amplified product during PCR and the HRM process to derive the Tm value.

Table 2. Oligonucleotides of primers used for high-resolution melting (HRM) analysis.

\begin{tabular}{|c|c|c|c|}
\hline Primer HRM & $5^{\prime}-3^{\prime}$ & $\mathrm{Ta}\left({ }^{\circ} \mathrm{C}\right)$ & Expected size (bp) \\
\hline HRM_matK1F & СТTCTTATTTACGATTAACATCTTCT & 57 & 170 \\
\hline HRM_matK1R & TTTCTTTGATATCGAACATAATG & & \\
\hline HRM_psbA-trnH F & ATGGGGTATTGTTATTTTGTTTTG & 57 & $115-150$ \\
\hline HRM_psbA-trnH R & TGTATTTAATATACATATATACAATCTA & & \\
\hline HRM_rbcLBF & GGTACATGGACAACTGTGTGGA & 57 & 150 \\
\hline HRM_rbcLBR & ACAGAACCTTCTTCAAAAAGGTCTA & & \\
\hline HRM_trnL1F & TGGGCAATCCTGAGCCAAATC & 57 & 120 \\
\hline HRM_trnL1R & AACAGCTTCCATTGAGTCTCTGCACCT & & \\
\hline
\end{tabular}

The RT-PCR amplification was performed on a 48-well Helixis plate using an initial denaturing step at $95^{\circ} \mathrm{C}$ for $5 \mathrm{~min}$ followed by 35 cycles of $95^{\circ} \mathrm{C}$ for $30 \mathrm{~s}, 57^{\circ} \mathrm{C}$ for $30 \mathrm{~s}$, and $72^{\circ} \mathrm{C}$ for $20 \mathrm{~s}$. Fluorescence data were acquired at the end of each extension step during the PCR 
cycles. Subsequently, the PCR amplicons were denatured for $\mathrm{HRM}$ at $95^{\circ} \mathrm{C}$ for $15 \mathrm{~s}$, and then annealed at $50^{\circ} \mathrm{C}$ for $15 \mathrm{~s}$ to form random-DNA duplexes. The RT-PCR HRM protocol collected fluorescence data at $0.1^{\circ} \mathrm{C}$ temperature increments. The EcoStudy Software v 5.0 was used to plot a normalized curve of decreasing fluorescence with increasing temperature. The negative derivative of fluorescence $(F)$ over the temperature $(T)(d F / d T)$ curve gives the Tm. To generate normalized melting curves and difference melting curves (Wittwer et al., 2003), pre- and post-melt normalization regions were set to define the main temperature boundaries of the normalized and difference plots with $U$. siamensis set as the reference species.

\section{RESULTS}

\section{DNA mining}

Sequences for four selected plastid regions (matK, $p s b \mathrm{~A}-t r n \mathrm{H}, r b c \mathrm{~L}$, and $t r n \mathrm{~L}$ ) were retrieved from GenBank (NCBI) for each of the species in the genus Uvaria (Annonaceae) (Table S1). The primary number of resulting sequences downloaded from GenBank of matK, psbA-trnH, rbcL, and trnL were $86,67,94$, and 98, respectively. The length of the downloaded sequences ranged from 751 to $1353 \mathrm{bp}$ for matK, 209 to $428 \mathrm{bp}$ for $p s b \mathrm{~A}-\mathrm{trnH}, 446$ to $1566 \mathrm{bp}$ for rbcL, and 194 to $1421 \mathrm{bp}$ for trnL. Across all search results from GenBank, the largest group of sequences in the Uvaria genus (98 records) retrieved belonged to $t r n \mathrm{~L}$ region on the chloroplast genome. However, the length of $r b c \mathrm{~L}$ was the longest at $1566 \mathrm{bp}$ and the shortest was psbA-trnH, which is of $209 \mathrm{bp}$ (Table 3).

Table 3. Sequences for selected plastid regions (matK, $p s b \mathrm{~A}-t r n \mathrm{H}, r b c \mathrm{~L}$, and $t r n \mathrm{~L}$ ) retrieved from GenBank (NCBI).

\begin{tabular}{|c|c|c|c|c|c|c|}
\hline \multirow[t]{2}{*}{ Regions } & \multirow[t]{2}{*}{ Search result from GenBank } & \multicolumn{2}{|c|}{ Length (bp) } & \multirow[t]{2}{*}{ Sequences in analysis dataset } & \multirow[t]{2}{*}{ Length (bp) } & \multirow[t]{2}{*}{ Species } \\
\hline & & Min & Max & & & \\
\hline matK & 86 & 751 & 1353 & 73 & 360 & 61 \\
\hline psbA-trnH & 67 & 209 & 428 & 49 & 360 & 48 \\
\hline$r b c L$ & 94 & 446 & 1566 & 77 & 360 & 63 \\
\hline $\operatorname{trnL}$ & 98 & 194 & 1421 & 50 & 360 & 45 \\
\hline
\end{tabular}

Low-quality sequences and accessions without specified herbarium vouchers were discarded. After sorting out of irrelevant, unverified, ambiguous, and outnumbered sequences followed by alignment and manual editing, the number of remaining sequences in analysis dataset of matK, psbA-trnH, rbcL, and trnL were reduced to 73, 49, 77, and 50 covering 61, 48, 63, and 45 species, respectively. After filtering sequences with criteria mentioned above, $r b c L$ was the largest group of samples covering the highest number of species (Table 3).

All processed sequences were subjected to a comparison of variable sites with 360 $\mathrm{bp}$ being the total length of the analyzed sequences of each region. At $31.7 \%$ (114 of $360 \mathrm{bp}$ ), the psbA-trnH fragment sequences were observed to have higher nucleotide variation than the fragment sequences of the other regions (Figure 1). The relative nucleotide variation within fragment sequences was as follows: $p s b \mathrm{~A}-t r n \mathrm{H}>$ matK $>r b c \mathrm{~L}>\operatorname{trnL}$ (Table 4 and Figure 1). However, within the variable sites, if any site contains at least two types of nucleotides, and if at least two of them occur with a minimum frequency of two, it is then classified as parsimony-informative site. The percentage of parsimony-informative sites found on each plastid region was $76.1 \%$ (35 of 46), $64 \%$ (73 of 114), 69.1\% (29 of 42), and 30\% (12 of 40) for matK, psbA-trnH, rbcL, and trnL, 
respectively (Table 4 and Figure 2). The HRM primers derived from these four selected regions were used in HRM analysis.
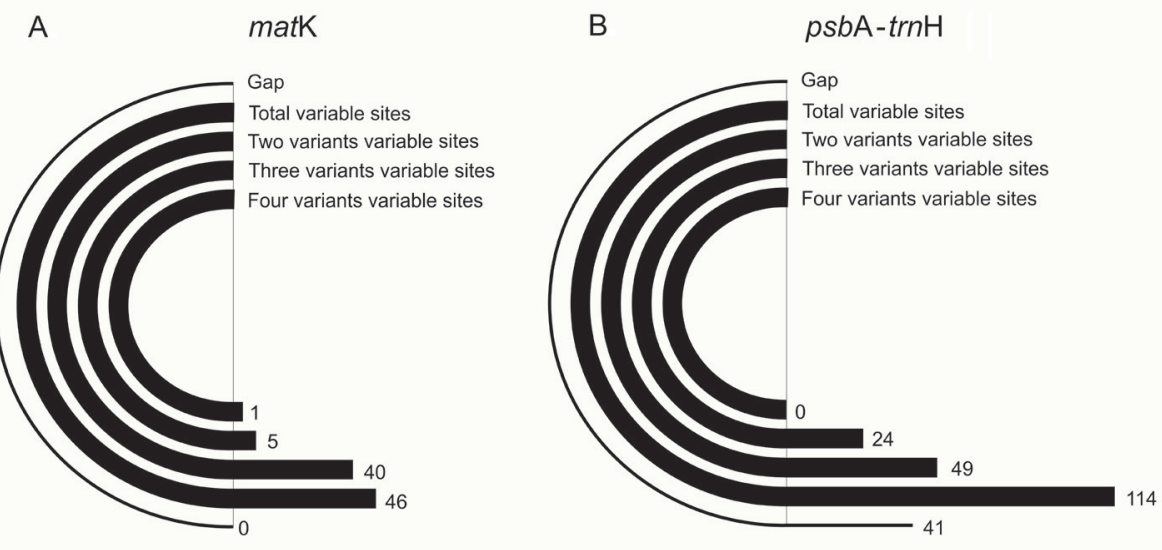

C $r b c L$

D
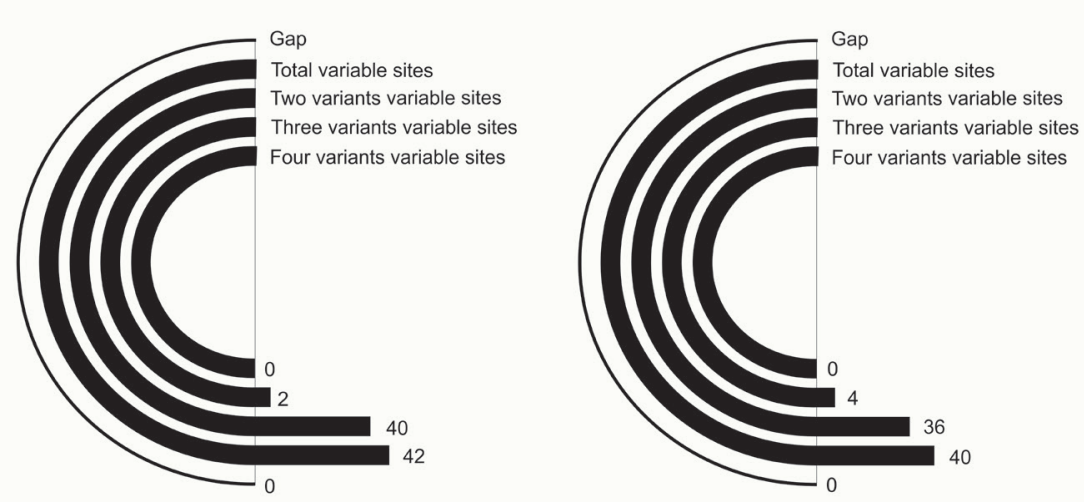

Figure 1. Relative nucleotide variation within fragment sequences of the four chloroplast regions: A. matK; B. psbA$t r n \mathrm{H}$; C. $r b c \mathrm{~L}$; and D. $t r n \mathrm{~L}$. Details on nucleotide variants found on the variation sites were shown as two to the maximum of four.

Table 4. Characteristics of sequences and primers used for high-resolution melting analysis.

\begin{tabular}{lcccc}
\hline Regions & matK & psbA-trnH & $r b c$ L & trnL \\
\hline Available species & 70 & 66 & 68 & 70 \\
Conserved sites (\%) & $314(87.2)$ & $205(56.9)$ & $318(88.3)$ & $320(88.9)$ \\
Variable characters (\%) & $46(12.8)$ & $114(31.7)$ & $42(11.7)$ & $40(11.1)$ \\
Parsimony-informative site (\%) & $35(76.1)$ & $73(64.0)$ & $29(69.1)$ & $12(30.0)$ \\
Conserved forward primer/total (\%) & $14 / 26(53.8)$ & $20 / 24(83.3)$ & $22 / 22(100)$ & $21 / 21(100)$ \\
Conserved reverse primer/total (\%) & $12 / 23(52.2)$ & $24 / 28(85.7)$ & $24 / 25(96.0)$ & $27 / 27(100)$ \\
Average \%GC content & 35.9 & 29.9 & 47.4 & 36.1 \\
\hline
\end{tabular}




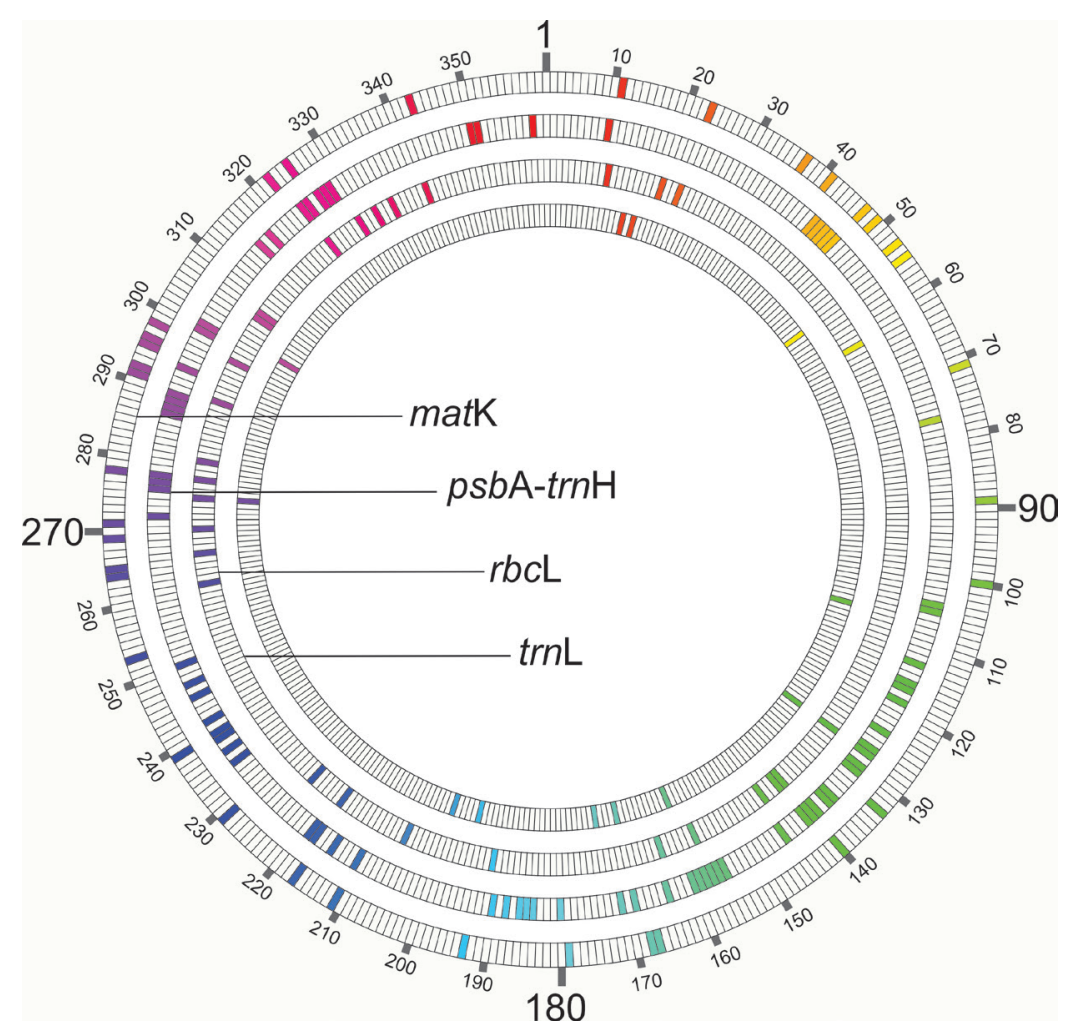

Figure 2. Parsimony-informative site within fragment sequences of the four chloroplast regions: from outside matK, $p s b \mathrm{~A}-t r n \mathrm{H}, r b c \mathrm{~L}$, and $t r n \mathrm{~L}$. The numbers indicate nucleotide position 1-360 bp of the analyzed fragments. Color highlight represents the variable site.

\section{Evaluation of four primer pairs used in Bar-HRM}

Four primer pairs of four chloroplast regions were used in HRM analysis (Table 2). These four primer sets amplified products from matK, $p s b \mathrm{~A}-t r n \mathrm{H}, r b c \mathrm{~L}$, and $t r n \mathrm{~L}$ and were expected to yield amplicons to the sizes of $170,115-150,150$, and $120 \mathrm{bp}$, respectively. The forward and reverse matK primers matched the consensus sequence of the downloaded species at the binding sites in only 14 of 26 sites (53.8\%) and 12 of 23 sites (52.2\%), respectively (Table 4$)$. Similarly, psbA-trnH primers matched the consensus sequence of the downloaded species at the binding sites in 14 of 24 sites (58.3\%) of forward primer and 16 of 28 sites (57.1\%) of reverse primer. The average \%GC content of amplicons was calculated in order to predict the variation in melting curves for the different markers. The psbA-trnH had the lowest average \%GC content, with $29.9 \%$, followed by matK, trnL, and $r b c \mathrm{~L}$, with $35.9,36.1$, and $47.4 \%$, respectively (Table 4).

HRM analysis was performed in triplicates to establish the Tm for each primer set. The shapes of the melting curves were analyzed using the EcoStudy Software v 5.0 to distinguish the different plant species. Performing HRM analysis using a set of primers of the four selected regions would yield amplicons ranging from 100 to $170 \mathrm{bp}$ as mentioned above. Reed and Wittwer (2004) found that amplicons suitable for HRM analysis should be 300 bp or less for optimal results. 
However, both sequence length and the nucleotide variation within sequences influence the dissociation energy of the base pairs and result in different Tm values. The psbA-trn H amplicon sequences were observed to have higher nucleotide variation $(31.7 \%)$ than the amplicons of the other regions, and thus the psbA-trnH primer pair in this study was expected to be a suitable primer for HRM analysis for identifying tested plant species. On the other hand, in this study, none of amplicons could be detected from HRM experiments using matK primer set. High universality at the initial bases of the primer site is crucial for primer annealing and subsequent elongation initiation by the DNA polymerase. The forward and reverse matK primers were found to match the consensus sequence of the Uvaria species at the binding sites as just about half of the primer length (Table 4). This could explain why we cannot get any results (amplicons) from performing HRM using the matK primer pair. In contrast, $r b c \mathrm{~L}$ and $t r n \mathrm{~L}$ primer pairs have $100 \%$ and $p s b \mathrm{~A}-\mathrm{trn \textrm {H }}$ 83.3\% match with the Uvaria species sequences at the binding sites, therefore, amplicons from these primer sets could be generated.

\section{Species identification of the target plant}

The $r b c \mathrm{~L}$ and $t r n \mathrm{~L}$ primer pairs were used in HRM analysis. The amplicons were analyzed to determine the Tm and the results presented by means of conventional derivative plots, which show the Tm value for the amplified fragment from each species. The melt curve is generated by slowly melting the DNA of tested plant species through a range of temperatures in the presence of a dsDNA binding dye. The melting temperature peaks of the Uvaria plant species are calculated as Tm. HRM analysis with the $r b c L$ primer pair failed to distinguish between the two closely related Uvaria species ( $U$. longipes and $U$. wrayi) as the melt curves of the two species could not be distinguished from each other (Figure 3A), although the melt curve of $U$. siamensis is clearly distinct from the two species. Also none of the tested species could be distinguished using trnL primers (Figure $3 \mathrm{~B}$ ). Therefore, this primer pair of $r b c L$ and $t r n L$ is not suitable for identifying the target sample. The $r b c L$ did not give satisfactory results in this study although it has been suggested as a core marker for plant DNA barcode. Also, Bar-HRM using $r b c L$ was reported to be useful in authenticating herbal species in commercial products (Osathanunkul et al., 2015). In contrast, the individual melting curves were reproducibly achieved using $p s b \mathrm{~A}-t \mathrm{rnH}$ primers from each of the three different Uvaria species in triplicate analyses (Figure $4 \mathrm{~A}$ and $\mathrm{B}$ ). Thus, the method is applicable for identifying the target plant species. In Figure 4A, there are clearly separate groups of the plant samples as $U$. longipes, $U$. wrayi, and $U$. siamensis. Melt curve of the target plant was found to be in a $U$. wrayi cluster with a $90 \%$ confidence interval. This indicates that the target plant could be identified as $U$. wrayi. The whole process from start until species identification took just about $2 \mathrm{~h}$. Such findings suggest that Bar-HRM may be used as a powerful aiding tool for plant species identification and for discriminating closely related species, rather than the traditional method of checking morphological characteristics, which would involve waiting for about two years for the flowering to occur.

\section{Confirmation of Bar-HRM}

DNA of all samples (two samples of $U$. longipes (L1 and L2), two samples of $U$. wrayi (W1 and W2), one of $U$. siamensis (S), and the unknown sample (U)) were sent to be sequenced for confirming the Bar-HRM results. To identify similarity of the samples, a comparison of homologous 

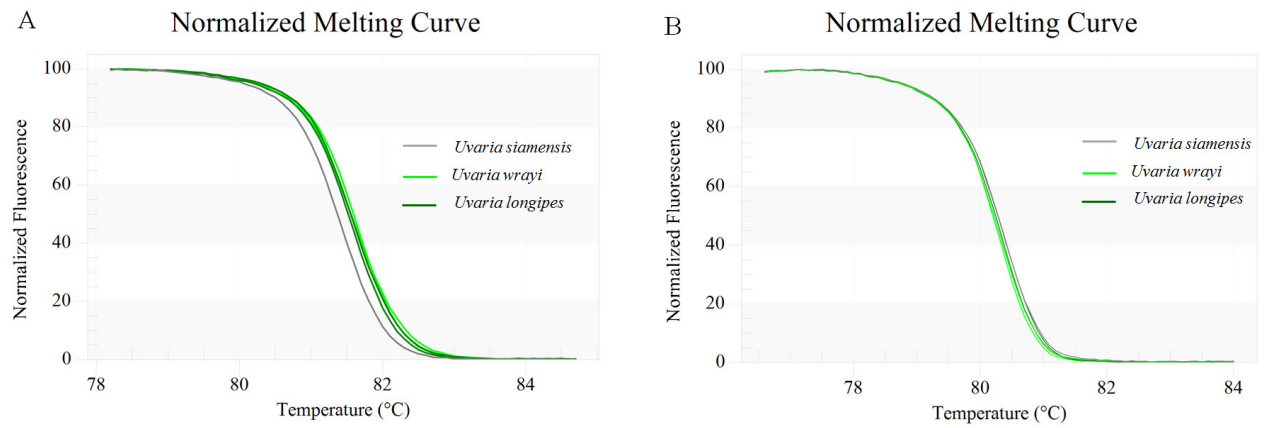

Figure 3. Representative profiles of the melting curves obtained by Bar-HRM using (A) the rbcL primer pair and (B) the $t r n L$ primer pair. The species are indicated.
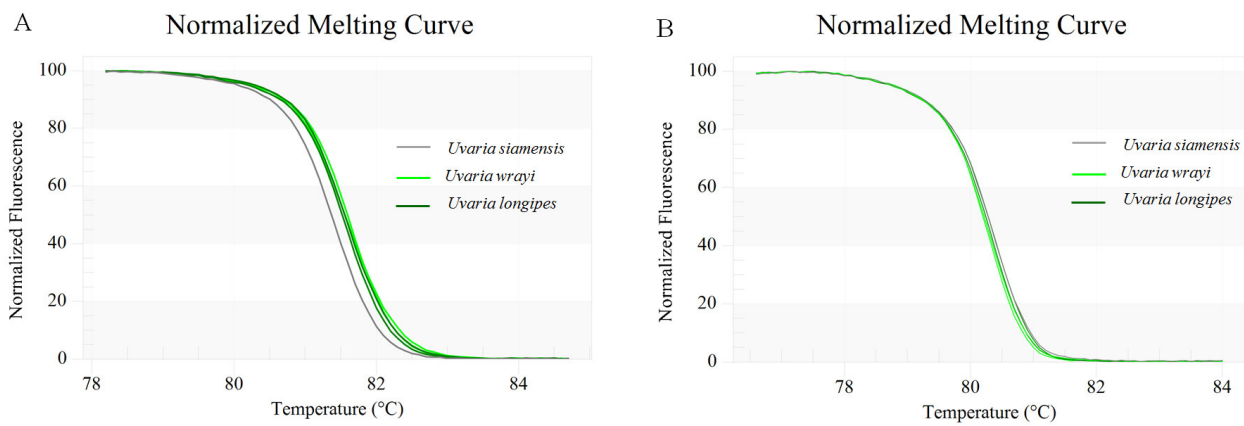

Figure 4. Melting curve profiles of amplicons obtained from $p s b A-t r n \mathrm{H}$ primer set generated by high-resolution melting (HRM) analysis. A. The normalized plot shows the differentiation of melting each temperature (Tm) of species. B. Difference melting curve with Uvaria siamensis as baseline.

sequences using sequence alignment techniques was carried out. Sequences of $\mathrm{L} 1$ and $\mathrm{L} 2$ contain $100 \%$ base similarity in all four regions (matK, $p s b \mathrm{~A}-t r n \mathrm{H}, r b c \mathrm{~L}$, and $t r n \mathrm{~L})$. Likewise, $\mathrm{W} 1, \mathrm{~W} 2$, and $\mathrm{U}$ share $100 \%$ similarity in their nucleotide composition. All four gene sequences were deposited in GenBank (Table 5). Therefore, these data could be used to support our Bar-HRM results that indicated the unknown sample as $U$. wrayi.

Table 5. Sequences deposited in GenBank with accession number.

\begin{tabular}{lccccc}
\hline Species & Samples & \multicolumn{2}{c}{ Accession number } \\
\cline { 3 - 5 } & & matK & psbA-trnH & rbcL & KRnL \\
\hline Uvaria longipes & L1 & KR824531 & KR905569 & KR905574 & KR905579 \\
Uvaria longipes & L2 & KR824532 & KR905570 & KR905575 & KR905580 \\
Uvaria wrayi & W1 & KR824533 & KR905571 & KR905576 & KR905581 \\
Uvaria wrayi & W2 & KR824534 & KR905572 & KR905577 & KR905582 \\
Uvaria wrayi & $\mathrm{U}$ & KR905584 & KR905585 & KR905586 & KR905587 \\
Uvaria siamensis & S & KR824535 & KR905573 & KR905578 & KR905583 \\
\hline
\end{tabular}




\section{DISCUSSION}

In this study, we describe the development of a hybrid method, Bar-HRM, for identification of a plant sample of Uvaria species, of which not all important morphological features could be collected. The target species plant was at an early age stage, with no flowers produced. The two closely related species, $U$. longipes and $U$. wrayi, share several morphological similarities. Flowers of these plants are critical in species identification of these plants. However, it usually takes several years for the plant to flower, and in our case we would have had to wait for two more years.

The method developed here was proven to be effective in distinguishing between three Uvaria species ( $U$. longipes, $U$. siamensis, and $U$. wrayi). The DNA extracted from tested samples yielded a specific amplification product with the $p s b \mathrm{~A}-t r n \mathrm{H}, r b c \mathrm{~L}$, and $t r n \mathrm{~L}$ primers but not matK set. The matK locus is one of the most variable plastid coding regions and has high interspecific divergence and good discriminatory power. However, it can be difficult to amplify with the standard barcoding primers due to high substitution rates at the primer sites (CBOL Plant Working Group, 2009; Hollingsworth, 2011). In addition to the matK and rbcL barcodes, other regions, psbA-trnH and $t r n \mathrm{~L}$ were suggested as supplementary DNA barcodes for plants (Hollingsworth, 2011; Li et al., 2011). Only the use of psbA-trnH primers reported here is good for the tested Uvaria species identification. The normalized HRM curves for the amplicons, from the two Uvaria species and the target species, based on HRM analysis with barcode marker psbA-trnH were easily to spot, and the target sample could be successfully assigned to the $U$. wrayi species.

Thus, Bar-HRM analysis was proven to be a fast and cost-effective method for plant species differentiation and/or identification.

\section{Conflicts of interest}

The authors declare no conflict of interest.

\section{ACKNOWLEDGMENTS}

Research supported by the CMU Research Group Grant (Chiang Mai University).

\section{REFERENCES}

CBOL Plant Working Group (2009). A DNA barcode for land plants. Proc. Natl. Acad. Sci. USA 106: 12794-12797. http://dx.doi.org/10.1073/pnas.0905845106

Chatrou LW, Pirie MD, Erkens RHJ, Couvreur TLP, et al. (2012). A new subfamilial and tribal classification of the pantropical flowering plant family Annonaceae informed by molecular phylogenetics. Bot. J. Linn. Soc. 169: 5-40 http://dx.doi.org/10.1111/j.1095-8339.2012.01235.x.

Couvreur TL, Richardson JE, Sosef MS, Erkens RH, et al. (2008). Evolution of syncarpy and other morphological characters in African Annonaceae: a posterior mapping approach. Mol. Phylogenet. Evol. 47: 302-318.http://dx.doi.org/10.1016/j. ympev.2008.01.018

Doyle JA and Le Thomas A (1994). Cladistic analysis and pollen evolution in Annonaceae. Acta Bot. Gallica 141: 149-170. http://dx.doi.org/10.1080/12538078.1994.10515148

Fazekas AJ, Burgess KS, Kesanakurti PR, Graham SW, et al. (2008). Multiple multilocus DNA barcodes from the plastid genome discriminate plant species equally well. PLoS One 3: e2802.http://dx.doi.org/10.1371/journal.pone.0002802

Fazekas AJ, Kesanakurti PR, Burgess KS, Percy DM, et al. (2009). Are plant species inherently harder to discriminate than animal species using DNA barcoding markers? Mol. Ecol. Resour. 9 (Suppl s1): 130-139. http://dx.doi.org/10.1111/j.1755-0998.2009.02652.x 
Franzini PZN, Dippenaar-Schoeman AS, Yessoufou K and Van der Bank FH (2013). Combined analyses of genetic and morphological data indicate more than one species of Cyrtophora (Araneae: Araneidae) in South Africa. Int. J. Mod. Biol. Res. 1: 21-34.

Fries RE (1959). Annonaceae. In: Die natürlichen Pflanzenfamilien. 2nd edn. (Engler A and Prantl K, eds.). Duncker \& Humblot, Berlin, 1-171.

Hajibabaei M, Janzen DH, Burns JM, Hallwachs W, et al. (2006). DNA barcodes distinguish species of tropical Lepidoptera. Proc. Natl. Acad. Sci. USA 103: 968-971.http://dx.doi.org/10.1073/pnas.0510466103

Hebert PD, Cywinska A, Ball SL and deWaard JR (2003). Biological identifications through DNA barcodes. Proc. Biol. Sci. 270: 313-321.http://dx.doi.org/10.1098/rspb.2002.2218

Hebert PDN, Penton EH, Burns JM, Janzen DH, et al. (2004). Ten species in one: DNA barcoding reveals cryptic species in the neotropical skipper butterfly Astraptes fulgerator. Proc. Natl. Acad. Sci. USA 101: 14812-14817. http://dx.doi.org/10.1073/pnas.0406166101

Hebert PDN, Dewaard JR and Landry JF (2010). DNA barcodes for 1/1000 of the animal kingdom. Biol. Lett. 6: $359-362$. http://dx.doi.org/10.1098/rsbl.2009.0848

Hollingsworth PM (2011). Refining the DNA barcode for land plants. Proc. Natl. Acad. Sci. USA 108: 19451-19452.http://dx.doi. org/10.1073/pnas.1116812108

Hutchinson J (1923). Contributions towards a phylogenetic classification of flowering plants II. The genera of Annonaceae. Bull. Misc. Inform., Royal Botanic Gardens, Kew 1923: 241-261.

Keßler PJA (1993). Annonaceae. Flowering Plants - Dicotyledons Springer-Verlag (Kubitzki K, et al. eds.). Berlin, Heidelberg, 2: 93-129.

Kool A, de Boer HJ, Krüger A, Rydberg A, et al. (2012). Molecular identification of commercialized medicinal plants in southern Morocco. PLoS One 7: e39459.http://dx.doi.org/10.1371/journal.pone.0039459

Kress WJ and Erickson DL (2007). A two-locus global DNA barcode for land plants: the coding rbcL gene complements the non-coding trnH-psbA spacer region. PLoS One 2: e508.http://dx.doi.org/10.1371/journal.pone.0000508

Larkin MA, Blackshields G, Brown NP, Chenna R, et al. (2007). Clustal W and Clustal X version 2.0. Bioinformatics 23: 29472948.http://dx.doi.org/10.1093/bioinformatics/btm404

Li DZ, Gao LM, Li HT, Wang H, et al.; China Plant BOL Group (2011). Comparative analysis of a large dataset indicates that internal transcribed spacer (ITS) should be incorporated into the core barcode for seed plants. Proc. Natl. Acad. Sci. USA 108: 19641-19646.http://dx.doi.org/10.1073/pnas.1104551108

Meade CV (2005). A new species of Uvaria (Annonaceae) from Southeast Asia. Adansonia 27: 17-20.

Mitchell A(2008). DNA barcoding demystified. Aust. J. Entomol. 47: 169-173. http://dx.doi.org/10.1111/j.1440-6055.2008.00645.x

Mols JB, Gravendeel B, Chatrou LW, Pirie MD, et al. (2004). Identifying clades in Asian Annonaceae: monophyletic genera in the polyphyletic Miliuseae. Am. J. Bot. 91: 590-600.http://dx.doi.org/10.3732/ajb.91.4.590

Osathanunkul M, Madesis P and de Boer H (2015). Bar-HRM for authentication of plant-based medicines: evaluation of three medicinal products derived from Acanthaceae species. PLoS One 10: e0128476. http://dx.doi.org/10.1371/journal.pone.0128476

Pirie MD, Chatrou LW, Mols JB, Erkens RHJ, et al. (2006). 'Andean-centred' genera in the short-branch clade of Annonaceae: testing biogeographical hypotheses using phylogeny reconstruction and molecular dating. J. Biogeogr. 33: 31-46. http://dx.doi.org/10.1111/j.1365-2699.2005.01388.x

Rainer H and Chatrou LW (2006). AnnonBase: world species list of Annonaceae. Annonaceae Working Group. Available at [http://www.sp2000.org and http://www.annonaceae.org]. Accessed December 4, 2011.

Reed GH and Wittwer CT (2004). Sensitivity and specificity of single-nucleotide polymorphism scanning by high-resolution melting analysis. Clin. Chem. 50: 1748-1754.http://dx.doi.org/10.1373/clinchem.2003.029751

Reja V, Kwok A, Stone G, Yang L, et al. (2010). ScreenClust: Advanced statistical software for supervised and unsupervised high resolution melting (HRM) analysis. Methods 50: S10-S14.http://dx.doi.org/10.1016/j.ymeth.2010.02.006

Ririe KM, Rasmussen RP and Wittwer CT (1997). Product differentiation by analysis of DNA melting curves during the polymerase chain reaction. Anal. Biochem. 245: 154-160.http://dx.doi.org/10.1006/abio.1996.9916

Särkinen T, Staats M, Richardson JE, Cowan RS, et al. (2012). How to open the treasure chest? Optimising DNA extraction from herbarium specimens. PLoS One 7: e43808.http://dx.doi.org/10.1371/journal.pone.0043808

Sass C, Little DP, Stevenson DW and Specht CD (2007). DNA barcoding in the cycadales: testing the potential of proposed barcoding markers for species identification of cycads. PLoS One 2: e1154.http://dx.doi.org/10.1371/journal.pone.0001154

Stoeckle MY, Gamble CC, Kirpekar R, Young G, et al. (2011). Commercial teas highlight plant DNA barcode identification successes and obstacles. Sci. Rep. 1: 42.http://dx.doi.org/10.1038/srep00042 PubMed

Tamura K, Peterson D, Peterson N, Stecher G, et al. (2011). MEGA5: molecular evolutionary genetics analysis using maximum likelihood, evolutionary distance, and maximum parsimony methods. Mol. Biol. Evol. 28: 2731-2739. http://dx.doi.org/10.1093/molbev/msr121 
Van der Bank HF, Greenfield R, Daru B, Yessoufou K (2012). DNA barcoding reveals micro-evolutionary changes and river system-level phylogeographic resolution of African silver catfish, Schilbeintermedius (Actinopterygii: Siluriformes: Schilbeidae) from seven populations across different African river systems. Acta Ichthyol. Piscat. 42: 307-320. http://dx.doi.org/10.3750/AIP2012.42.4.04

Wittwer CT, Reed GH, Gundry CN, Vandersteen JG, et al. (2003). High-resolution genotyping by amplicon melting analysis using LCGreen. Clin. Chem. 49: 853-860.http://dx.doi.org/10.1373/49.6.853

Zhou L, Su YCF and Saunders RMK (2009). Molecular phylogenetic support for a broader delimitation of Uvaria (Annonaceae), inclusive of Anomianthus, Cyathostemma, Ellipeia, Ellipeiopsis and Rauwenhoffia. Syst. Biodivers. 7: 249-258. http://dx.doi.org/10.1017/S1477200009003028.

\section{Supplementary material}

Table S1. Uvaria plant sequences of four plastid regions (matK, $p s b \mathrm{~A}-t r n \mathrm{H}, r b c \mathrm{~L}$, $t r n \mathrm{~L}$ ) were retrieved from GenBank (NCBI) for each of the species with Accession number. 